\title{
A COMPUTERIZED SYSTEM FOR DESIGNING OPTIMAL TREE- LINING IN PLANTING AREAS
}

\author{
Ismadi Md Badarudin ', Abu Bakar Md Sultan², Md Nasir Sulaiman³, Ali Mamat ${ }^{4}$, \\ Mahmud Tengku Muda Mohamed ${ }^{5}$ \\ ${ }^{1}$ Faculty of Computer and Mathematical Sciences, UiTM, Malaysia \\ ${ }^{2,3,4}$ Faculty of Computer Science and Information Technology, UPM, Malaysia \\ ${ }^{5}$ Faculty of Crop Sciences, UPM, Malaysia
}

\begin{abstract}
A computerized system for the selection of planting lining directions is to optimize tree planting areas. Therefore, this paper focuses on some issues of lining and the development strategies of system. Lining direction handle $60^{\circ}$ from the baseline is a common practice; however various areas coordinates, analyzing other lining directions $\left(1^{0}-90^{\circ}\right)$ may promote better the number of trees. The highest tree number by optimal lining direction indicates the area is fully utilized. However, to analyze all possible directions, by manual approach consume large time and effort leads to unanswered decision of optimal result determination. Thus an application named Tree-Lining Planning by Computerized System (LP-CS) does offer opportunities to determine tree numbers for the directions. The datasets by various coordinates represents areas were generated for the purposes of analysis. The generated results show that different lining angles promote better number of trees than $60^{\circ}$ lining direction. This indicates other directions might have tendency to be best lining direction because of variations in the area's coordinates.
\end{abstract}

Key Words: Tree-lining, Oil palm, optimization, Line-length representation, Integer programming

\section{INTRODCUTION}

The planting area utilization is important to balance the fall number of land size for planting activity which is replaced by the activities of industry, housing, factory and others. Chang (2002) reported that East Malaysia (Sabah and Sarawak) would have a challenge to land expand for oil palm. This statement was supported by Ramli (2003), he forecasted that in Malaysia new planting areas will drop from year 2010 onwards since land availability may decrease to make space for industrialization programs. The unlimited areas are a reason for land optimization in early planning, to yield the maximum benefit. Lining design considers as one of the preliminary planning in planting areas particularly involves in agricultural industries such as oil palm, coconut, rubber, forestry and others crops. Proper lining design improves the quality of crop growth, mitigates management responsibilities and increases planting density

Tree lining is an activity of preparing the direction of lines in a field that is made for planting seeds in. In the oil palm plantation, lining and holing are conducted with suitable seedlings, and the seedlings are then transplanted into a prepared planting area (Chemsain, 2000). The planning for lining is a continuing process due to yearly the replanting activities and the opening new planting areas. The process of replanting occurs when the old economical trees are removed after reaching maturity time, so that new seedlings are cultivated. According to Wilson and Piniau (2004), the replanting of a stand of oil palm is necessary when the palms have grown to such height that harvesting of $100 \%$ of the crop is no longer possible and the resultant crop losses reduce economic returns to an unacceptably low level. The lining planning process needs to be done regardless of some areas may practise the previous lining design. However, it is not recommended to keep previous lining designs for a prolonged time because the structure of the land may change. Therefore, large areas certainly require a new lining planning to yield better returns. Turner and Gillbunks (1974) stressed that correct planting is vital if transplanting shock and its concomitant adverse effects on growth and yield are to be minimized while also ensuring that the palms are correctly placed and consolidated for maximum development.

The process of replanting occurs when the obsolete trees are removed after reaching maturity and being cultivated. This is because of the palms have grown to such height that harvesting of $100 \%$ of the crop is no longer possible and the resultant crop losses reduce economic returns to an unacceptably low level (Wilson and Piniau, 2004). Turner and Gillbunks (1974) stressed that correct planting is vital if transplanting shock and its concomitant adverse effects on growth and yield are to be minimized while also ensuring that the palms are correctly placed and consolidated for maximum development.

Several studies on tree-lining issues have been deployed since it has potential to improve the production yield. The discussion on preparing the basic tree-lining (Harley, 1967) and on general guidelines to manage the tree-lining processes (Wilson and Piniau, 2004) by practicing $60^{\circ}$ angle of line-direction from the baseline has helped to minimize unused space. A proposal of planting direction from east to 
west was suggested by Lamprecht (1989) to more effectively utilize favourable light conditions. However, Appanah, and Weinland (1993) recommended a north-south direction rather than an east-west direction to minimize the duration of sunlight falling on the seedlings. The three separate experiments comprise (1) planting line-direction; (2) planting line width; (3) and the line maintenance method. They noted that line-direction seems to have a little effect on survival or growth rate of the planted species. An endeavor was made to improve the lining technique by focusing on potential of a new line planting method that is based on enrichment planting in Peninsular Malaysia (Safa et al., 2004). Researchers found that the traditional technique of enrichment planting is associated with some drawbacks that lead to low growth performance of the seedlings

The optimum yield of a hectare of palms over a given period can only be determined by knowing of the potential cumulative yield of palms with different spacing. At a certain density the number of palms per hectare multiplied by the cumulative yield per palm becomes optimal. When plantations were first established spacing was determined by judging the probable spread of the palms' leaves under plantation condition. The adopted spacing varied from $8.5 \mathrm{~m}$ to $10.0 \mathrm{~m}$, and a triangular arrangement was usually employed. Such spacing gave between 115 and 160 palms per hectare as shown in table 1 (Harley, 1967). A concern of soil types to determine tree density in one hectare has been organized by Corley et al. (1973). The suitable densities of tree on coastal soils, good inland soils and poorer inland soils were 150,158 and 166 palms/ha respectively. He had proposed a compromised density at 158 palms/ha.

Table 1. Triangular Planting Distance for Tree Density in Frequent Use (Data From Harley)

\begin{tabular}{|cc|}
\hline $\begin{array}{c}\text { Planting } \\
\text { Distance } \\
\text { (meters) }\end{array}$ & $\begin{array}{c}\text { Tree } \\
\text { Number } \\
\text { 1 ha } \mathbf{( 2 . 4 7 1 ~ a c r e ) ~}\end{array}$ \\
\hline 10 & $115 / 116$ \\
9.5 & $127 / 128$ \\
$\mathbf{9}$ & $\mathbf{1 4 2 / 1 4 3}$ \\
8.5 & $159 / 160$ \\
\hline \hline
\end{tabular}

A distance of $9.0 \mathrm{~m}$ that refers to spacing between trees is a common planting distance. The use of the basic formula of calculating tree number according to an area size $(1.15 *$ number of hectare * $1000 /$ planting distance) produces 127 palms/ha. This formula refers to inconsideration of assigned tree on the area border. On the contrary, the consent of trees on the border promotes a better number between 142 and 143 trees (Harley, 1967; Turner and Gillbunks, 1974). An analysis by Jusoh et al. (2003) stated that an optimal number could yield $148 \mathrm{palms} / \mathrm{ha}$, contrary to the conventional practice of 136-148 palms/ha. According to Ian and Tayeb (2003), the optimum density may differ with the site, soil, management inputs and planting material. On peat soil, tree density can reach up to 200 palms/ha. In the certain circumstances of planting material, soil and climate, yields between 128 and 148 palms/ha could be obtained (OP, 2010).

According to the above discussion it is clear that the density of tree relies on planting distance, site and planting area. However density options in one hectare using same criteria of the above factors is the matter of tree density inconsistency. The unmentioned of the actual area coordinates used; hence the planting area coordinates influence the tree density is a new discovery. Moreover, it is supported by the illustration in figure $3,4,5,6,7$ and 8 of section 2, for an explanation of why the use of distinguished coordinates within in area produces an uncertain density.

The determination of a tree-lining design by taking into account the number of trees requires the constraints consideration such as sunlight, specific planting distance and land contour as the above discussion. However, many possible tree-lining designs with different dimensional borders, besides the above mentioned constraints make this design activity a cumbersome task. Moreover, the possibility of different line-direction angles between $1^{\circ}$ and $90^{\circ}$ from the baseline to be analyzed requires a large amount of time, effort and cost.

The various lining design according to the practitioner's experience does not guarantee the optimal, therefore to choose the best line-direction by this manual approach will eventually left unanswered decision from managerial department. To address this matter, computers seem to be a very helpful device tool for providing a set of all possible optimized solutions. A computerized system named treeLining Planning by Computerized System (LP-CS) was developed to generate the optimized solutions by integer programming strategy.

The ultimate objectives of this paper are to determine the LP-CS capability to determine the number of trees by changing the line-direction and to handle the analysis of possible solutions in acceptable time. With these objectives in mind, the remainder of this paper is organized as follows. Section 2 focuses on lining preparation and inconsistency of tree density. Section 3 discusses the solution strategies as an aspiration of the LP-CS development. Section 4 explains the experimental design comprises to represent the datasets and to analyze results; Section 5 provides the findings and discussion. Finally, in section 6 discusses our conclusions and the future directions of this work.

\section{LINING ISSUES}

This study focused on tree lining issues in oil palm planting areas. Because the current literature about preparing treelining is insufficient, we provide a systematic procedure based on our references and our discussion with practitioners. We also discuss the uncertainty regarding tree density and promote the line layout strategy that is expected to find the optimal density for a given planting area. 


\subsection{Steps for Preparing The Tree-Lining}

The initial step in the process of replanting is the setting of the baseline. The baseline is typically a line surveyed along the edge of the block, at $90^{\circ}$ to the centerline of the main road. The baseline is identified using triangles with $3 \mathrm{~m}, 4 \mathrm{~m}$,
$5 \mathrm{~m}$ of each line respectively. As shown in figure 1 , the angle formed by the $3 \mathrm{~m}$ side and the $4 \mathrm{~m}$ side of the triangle will be $90^{\circ}$. Figure 1 also shows the different degrees to the centerline produce different baseline designs

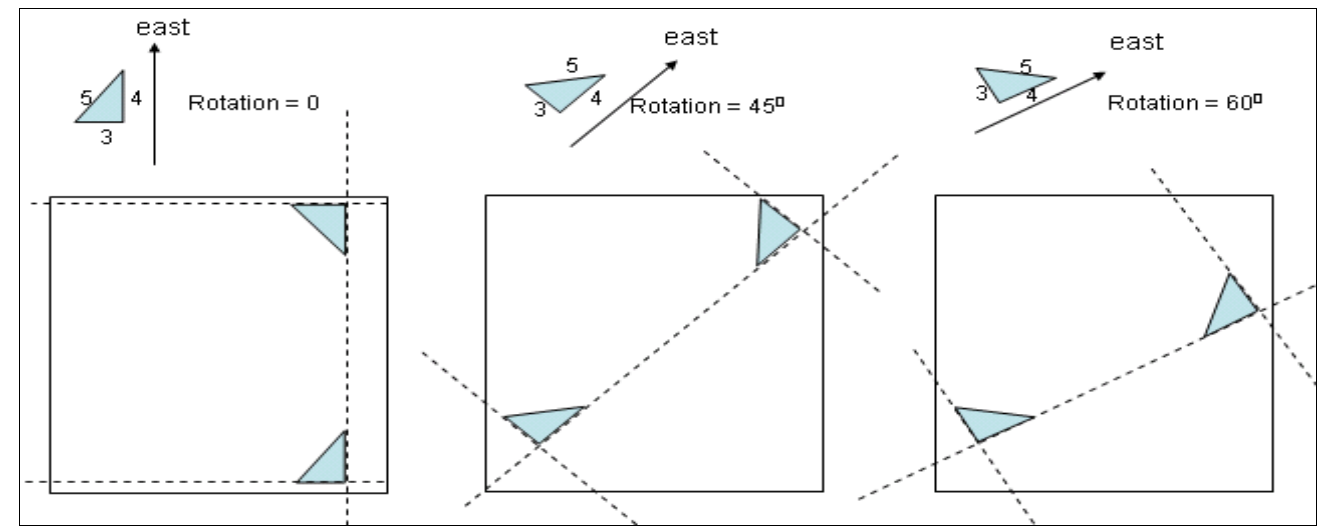

Fig. 1. Different Baseline Designs

To plan for the same distance between trees an equilateral triangle with all angles measuring $60^{\circ}$ is used. According to Turner and Gillbunks (1974), the distance between rows will be less than the planting distance between trees, and the inter row distance can be calculated by the formula: tree spacing in row multiply by 0.866 . The angle from one tree to the nearest in an adjacent row will be $180 / 3=60^{\circ}$. We set the baseline as our $y$-axis and use of the following steps (see Figure 2 for illustration of these steps):

Step1: Initial point starting from the origin coordinate $(\mathrm{y}=$ $0, \mathrm{x}=0)$.

Step2: Make a line by $60^{\circ}$ angle of the baseline using a straight pulled rope. Place marks along the line every $9 \mathrm{~m}$ on condition that keep the marks inside area border

Step3: The next line is placed at point of next $9 \mathrm{~m}$ along the $\mathrm{y}$-axis and remains $\mathrm{x}=0(\mathrm{x}=0, \mathrm{y}=\mathrm{y}+9)$, then repeat step2. This step3 is repeated until the placed line out of area border. The completion of step 3 and then it proceeds to step4.

Step4: Markings are placed along the $\mathrm{x}$-axis with separation dictated by the equation $\left[2 *\right.$ (sqrt (TreeDistance $^{2}-$ $\left.\left.\left.(\text { TreeDistance } / 2)^{2}\right)\right)\right]=15.6 \mathrm{~m}$ and remains $\mathrm{y}=0(\mathrm{x}=\mathrm{x}+15.6$, $\mathrm{y}=0$ ). Whenever a mark is placed along the $\mathrm{x}$-axis, step 2 is repeated. This step is repeated until the placed line out of area border.
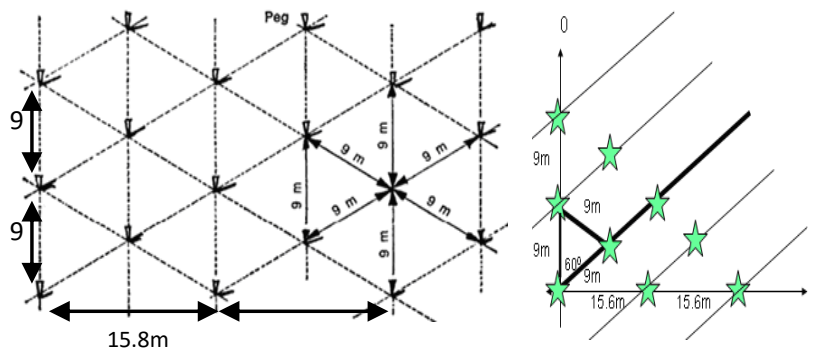

Fig. 2. Illustration of Lining Design by Using the Mentioned Steps

\subsection{Tree Density Inconsistencies}

Literature on planting areas optimization that focuses on the lining layout strategy for various planting areas shape has not been thoroughly explored yet, even though has a potential to improve optimal number of tree in planting areas.

From our observations, the tree density in a planting area is dependent on three variables which are area coordinates, line-direction and coordinates of the blocks. However, an inconsistent tree density often results from using these variables exclusively, and thus, the optimum number of trees for a given planting area can be difficult to determine.

Inconsistencies can result from a number of factors. First, if a given area is assigned different line-directions, a variable number of trees will result (see Figure 3 and 4 ). The tree number in figure 3 which is based on a $45^{\circ}$ line-direction is 11; while a $60^{\circ}$ line-direction, shown in figure 4 , results in a number of 12 . For other lines that consist of $1^{0}$ to $90^{\circ}$ linedirections, the number of trees may be different and thus a better result might be produced.

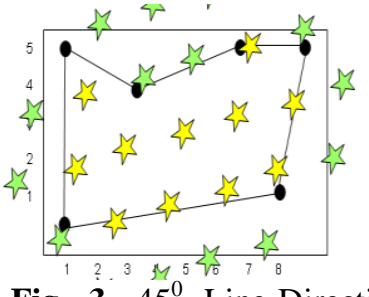

Fig. 3. $45^{0}$ Line-Direction Producing 11 Trees

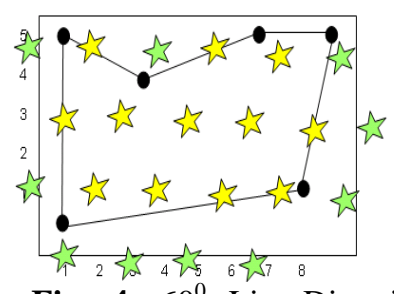

Fig. 4. $60^{\circ}$ Line-Direction Producing 12 Trees
Second, an area derived from various coordinates can leads to the different tree densities. Thus, the changes of the coordinate area may affect to number of trees. The situation can be illustrated by comparing figure 5 and figure 6 below. 
Both used $9.0 \mathrm{~m}$ for the planting distance, and refer to the origin coordinate $(0,0)$. The line-direction is $90^{\circ}$ from the baseline. When coordinate $\mathrm{x} 4=35$ in figure 5, 4 trees and $8 \mathrm{~m}$ of unused space result form the initial line, while in figure 6 , with coordinate $\mathrm{x} 4=36$, produces a better result with 5 trees and $0 \mathrm{~m}$ of unused space.

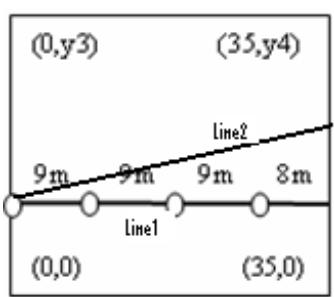

Fig. 5. Rectangular shape with coordinate $x 4=35$

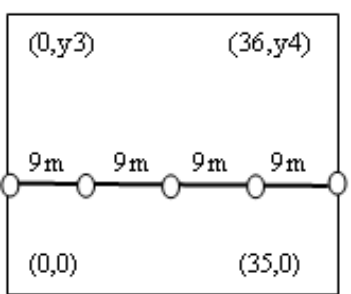

Fig. 6. Rectangular shape with coordinate $\mathrm{x} 4=36$
By slight modification of line 1 to line 2 as shown in figure 5, makes the line 2 longer. Let us imagine if the length of line2 is $36 \mathrm{~m}$, it promotes 5 trees in which more 1 than line1. The number will be more significant if the area size is larger that requires more repetition of lines, for instance 20 lines to be assigned into an area means line 2 produces more 20 trees than line1.

Third, land area shapes can be square, vertical rectangle or horizontal rectangle with sizes derived from their coordinate. The existence of different block coordinates even though they have same block size makes the optimum tree number difficult to determine. For example, the square and horizontal pattern produce a tree number of 55 and 54 respectively, even though both use the same area (see figure 7 ). A size of $1.5 \mathrm{~m}$ in figure 8 , which is based on a horizontal pattern, yields 23 trees, which is better than the square pattern that produces only 21 trees.

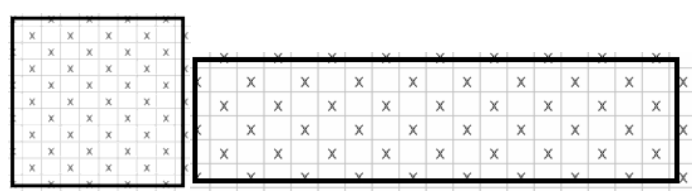

Fig. 7. Square Pattern $(2,2)$ and Horizontal Pattern $(4,1)$

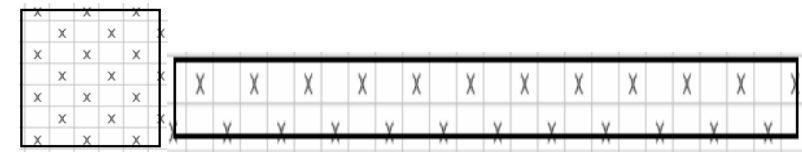

Fig. 8.Square $(1.23,1.23)$ and Horizontal Pattern $(5,0.3)$

The matters of inconsistent tree density require the linedirections of the different degrees angle to be analyzed in order to find the optimal tree number. We introduced a strategy called tree-lining planning $(L P)$ which is to determine the best line-direction for a given set of block divisions that has been early determined. The optimal treelining design is based on the best calculated tree number to be planted in the given planting area.

\section{THE DESIGN OF A COMPUTERISED SYSTEM FOR TREE-LINING PLANNING ( $L P$ -} CS)

\subsection{Problem Description}

With the solution of LP strategy, we simulated the process by the number of trees for each block with all possible linedirections. For the decision to divide a large area to several blocks intelligently was discussed in the previous paper by Ismadi et al. (2012). Table 2 represents the number of tree for blocks with their line-directions. The LP is based on the line-direction produces the highest number of tree for every block. The combination of B1L3 (B1 is block 1, L3 is linedirection 3), B2L2 and B3L3 is considered the best LP solution.

Table 2. Possible Solutions of Line-Directions for Blocks

\begin{tabular}{|l|c|c|c|c|c|}
\hline & Block 1 & Block 2 & Block 3 & $\ldots$ & Block n \\
\hline $\begin{array}{l}\text { Line- } \\
\text { Direction 1 }\end{array}$ & 140 & 130 & 154 & & $\mathrm{n}$ \\
\hline $\begin{array}{l}\text { Line- } \\
\text { Direction 2 }\end{array}$ & 139 & $\mathbf{1 3 8}$ & 150 & & $\mathrm{n}$ \\
\hline $\begin{array}{l}\text { Line- } \\
\text { Direction 3 }\end{array}$ & $\mathbf{1 4 2}$ & 135 & $\mathbf{1 5 5}$ & & $\mathrm{n}$ \\
\hline $\begin{array}{l}\text { : } \\
\text { Line- } \\
\text { Direction n }\end{array}$ & $\mathrm{n}$ & $\mathrm{n}$ & $\mathrm{n}$ & $\mathrm{n}$ & $\mathrm{n}$ \\
\hline
\end{tabular}

To obtain the optimal solution as discussed in table 2, the problem is considered to tractable which not so hard problem and it is able solved in polynomial time when the blocks have early been determined. However, the time requirement increases when the number of blocks increases. This is because of the process of determining the best tree number for every block requires the number of iterations which refers to the block number multiplied by the linedirection number. Therefore, the poor algorithm strategy leads to increase computational time that takes too long to analyze.

The algorithm based on integer optimization with repetition process that puts trees into an area will produce very large number of iterations. This large number of iterations was verified by a computerized performance analysis in multiobjective land use planning (Theodor et al., 2003). A strategy called cell representation in which one cell is equivalent to 1 x 1 coordinate grids was applied. According to Steward, identifying the suitable items to be assigned into for small areas is applicable, however the cells by $20 \times 20$ or $40 \times 40$ requires a great deal of computational time since the numerous iterations process are required.

For that reason, we proposed line-length representation in LP-CS application with intention to reduce the iteration process. The lines consist of determined number of tree is assigned into the blocks, will be expected significantly reduce the number of iterations. This is illustrated by figures 9 and 10 with their algorithm and iteration analysis below. 


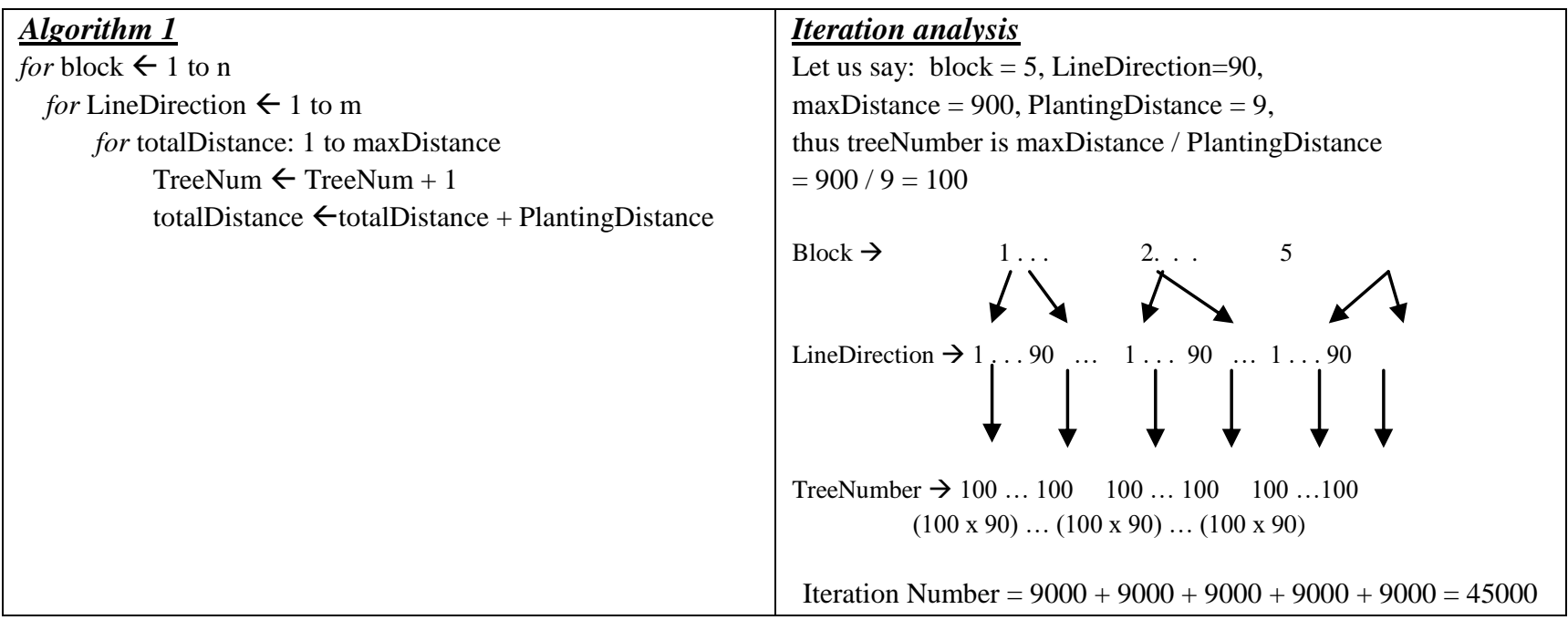

Fig. 9. Iteration Process with Tree-Number Representation

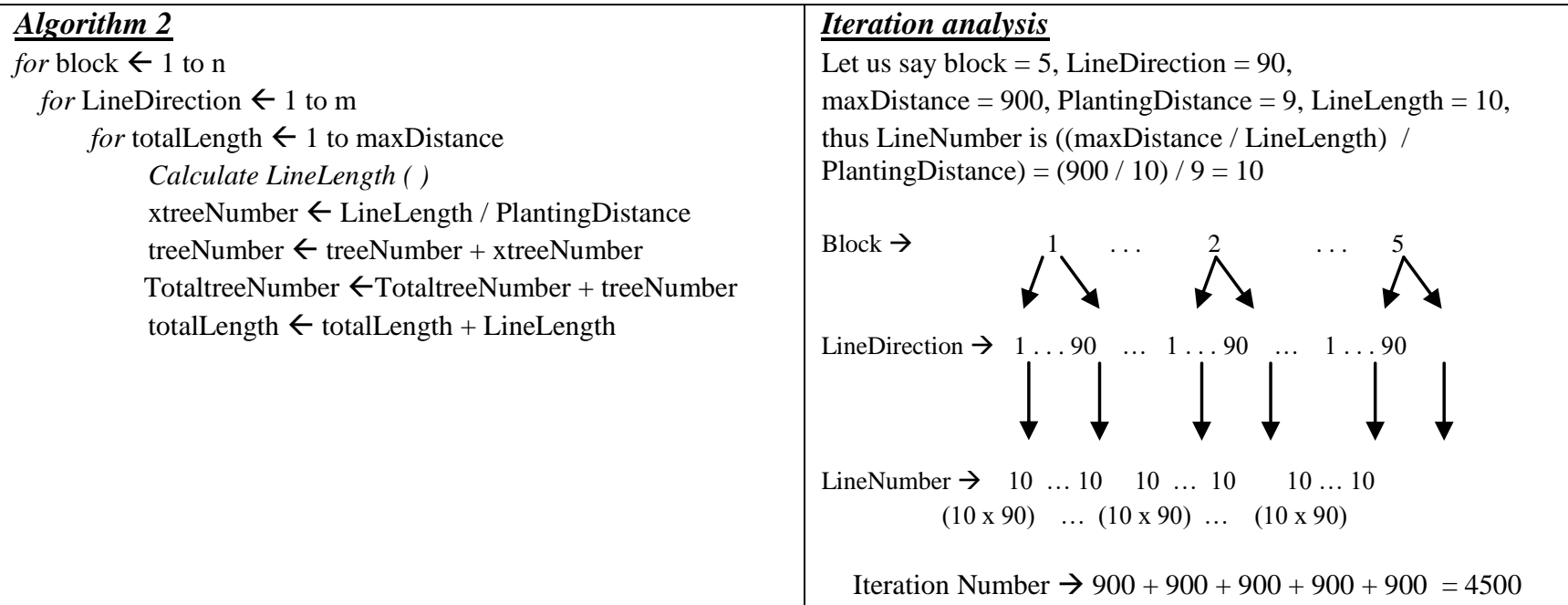

Fig. 10. Iteration Process with Line-Length Representation

Figure 9 shows that the five blocks and 90 numbers of different line-direction produce 45,000 iterations. This is because of for each assigned tree involves one increment of iteration number. The number of iterations in algorithm1 is based on the equation of $\sum_{b=l}^{b=n} \sum_{t=1}^{t=n}$ TreeNumber, where $(b$ is block and $t$ is line-direction). Figure 10 shows that algorithm 2 produces significantly less iterations with 4,500 since the iteration process refers to the number of lines that are assigned to the blocks. The equation of the algorithm 2 can be written as $\sum_{b=l}^{b=n} \sum_{l=l}^{l=n}$ LineNumber $_{b l}$

\subsection{Problem Formulation}

In this section, we formulated the strategy of assigning treelining based on actual practices in oil palm plantations. To obtain the triangular pattern with the same distance between trees, each angle degree of triangle must be $60^{\circ}$ of y-axis and thus, baseline was marked as $90^{\circ}$ of y-axis but for calculation purposes we replaced to $0^{0}$. Each tree will then be assigned according to the determined planting distance as shown in figure 11 . In this case, we recognized the line- direction is $60^{\circ}$. However, designing tree-lining with other line-direction angles of $1^{0}$ to $90^{\circ}$ require a modification of baseline to obtain $60^{\circ}$ of each angle of triangles and consequently maintain distance between trees same. For example, to find the $65^{\circ}$ line-direction, the baseline needs to be moved $+5^{0}$, as shown in figure 12 .

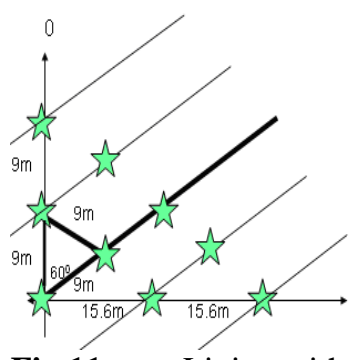

Fig.11. tree-Lining with $60^{\circ}$

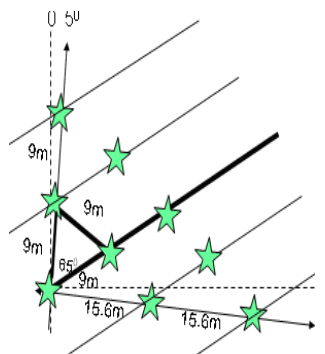

Fig.12. tree-Lining with $65^{0}$ 


\subsection{Solution Strategies}

There are two assumptions for the calculation of trees number and unused space. First, the area is fully utilized and second, trees can be assigned on the border of area. The strategy of line-length representation with intention to find a number of trees according to 90 possible of tree-lining is organized by the values determination of area coordinate (x1, y1; x2, y2; x3, y3 and $\mathrm{x} 4, \mathrm{y} 4)$, planting distance $(d)$, line-direction $(L D)$, baseline $(B L D)$, unused space $(U S)$ and line-length $(L L)$. Figure 13 shows the process of values derivation.

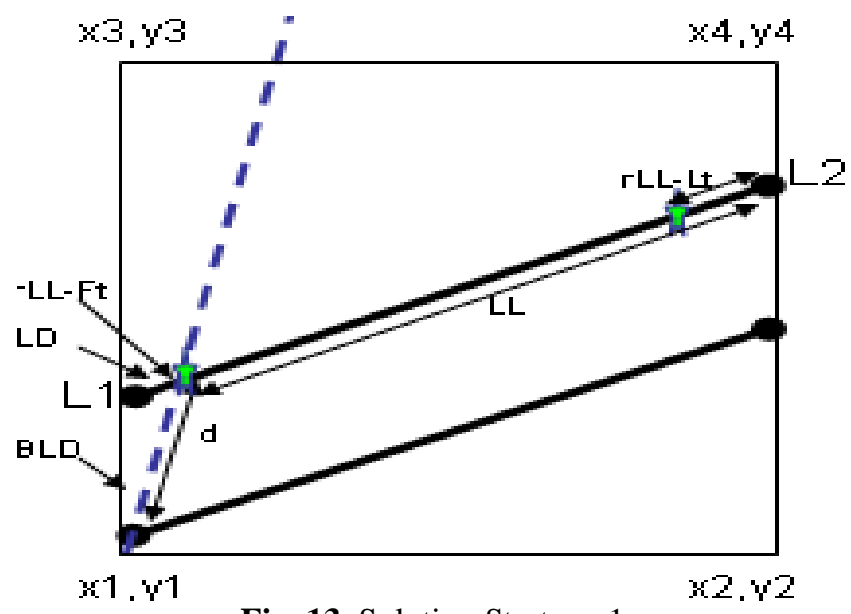

Fig. 13. Solution Strategy 1

The $d$ is distance between trees according to user defines. $L D$ is the degree of tree-lining that can be $1^{0}$ to $90^{\circ}$. BLD is marked based on gap between determined $L D$ and $60^{\circ}$, it is to identify the location of first tree to be assigned. $B L D$ vital to obtain the equilateral triangle (each angle is $60^{\circ}$ ), so that keep the $d$ same. $U S$ derives from $R L L-d / 2$, in which $R L L$ (Reminder Line Length) is summation of distance between first assigned tree and land border $(r L L-F t)$ and distance between last assigned tree and land border $(r L L-L t)$. $L L$ is distance between point $L 1$ and point $L 2$ and then the result is subtracted by $r L L-F t$. Number of trees is derived from $L L$ is divided by $d$.

In detail, to find the number of tree in a line, the length of lines for each row (r) must be calculated as shown in figure 14. Some inputs have to be identified such as coordinate area and distance between trees. To calculate the length of line refers to line either $\mathrm{y} 1=\mathrm{y} 2$ or $\mathrm{y} 1 \# \mathrm{y} 2$. If the line $\mathrm{y} 1$ equal to $\mathrm{y} 2$, the $\mathrm{x} 2$ coordinate is simply subtracted by $\mathrm{x} 1$, on the contrary condition, the equation will be $\operatorname{sqrt}\left[(\mathrm{x} 2-\mathrm{x} 1)^{2}+\right.$ $\left.(\mathrm{y} 2-\mathrm{y} 1)^{2}\right]$. This process is repeated by tree number summation after moving to next coordinate from (x1, y1) and $(\mathrm{x} 2, \mathrm{y} 2)$ coordinate to $(\mathrm{x} 2, \mathrm{y} 1+\mathrm{r})$ and $(\mathrm{x} 2, \mathrm{y} 2+\mathrm{r})$ respectively until the line exists out of the coordinate range.

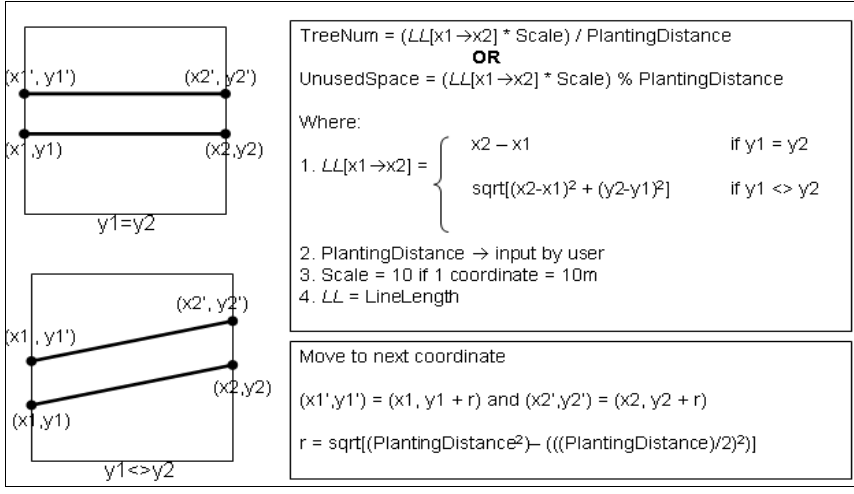

Fig. 14. Solution Strategy 2

The calculation process become complex when the L1 or L2 exceeds the coordinate area (as shown in figure 15). The point between $\mathrm{x} 3$ and $\mathrm{x} 4$ is indicated by $T$, whereas the point between $\mathrm{x} 1$ and $\mathrm{x} 2$ is indicated by $B$.

A trigonometry function was used to calculate the linelength. For line-length calculation between $L 1$ and $T$ is derived from the equation of $(y 3-L 1 / \operatorname{COS}(L D))$, whereas length between $L 1$ and $T$ is derived from the equation of $(L 2-y 2 / \operatorname{SIN}(x L D))$ where the $x L D$ derived from $90^{\circ}-L D$.

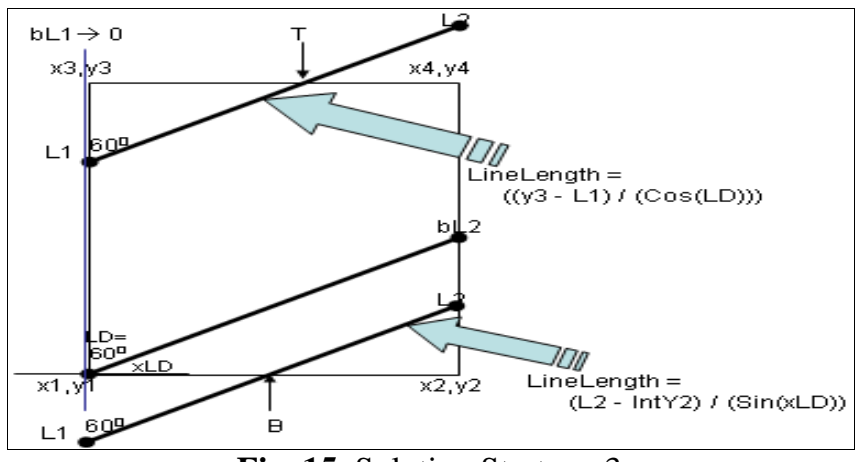

Fig. 15. Solution Strategy 3

For each calculated line length, the number of trees added 1 because of the trees are allowed to be assigned on the area border, in other words leaf canopy can beyond area border. Then, the total number of trees in the area is obtained by adding the number of trees in every line.

\subsection{Integer Programming Strategy Towards}

\section{Assigning Lines}

Integer Programming generates a complete solution that is guaranteed to find an optimal solution for every finite size instance of an optimization problem. However it might require time for exponential computation time in worse-case scenarios (Blum and Roli, 2003).

The main objective is to find the solution in producing optimal number of trees $(T)$ to be planted in an area. Thus the status of assigning line can be either accepted or not. The accepted lines are stated as 1 if line in range of land area, so that the number of tree can be obtained, otherwise is 0 . For analysis process of $T$, the tree number of every line- 
direction for each block needs to be calculated and then the comparison of the results will be implemented. Assume that each block has rectangular pattern with block coordinate $\mathrm{c} 1(\mathrm{x} 1, \mathrm{y} 1), \mathrm{c} 2(\mathrm{x} 2, \mathrm{y} 2), \mathrm{c} 3(\mathrm{x} 3, \mathrm{y} 3), \mathrm{c} 4(\mathrm{x} 4 \mathrm{y} 4)$ as shown in figure 16 .

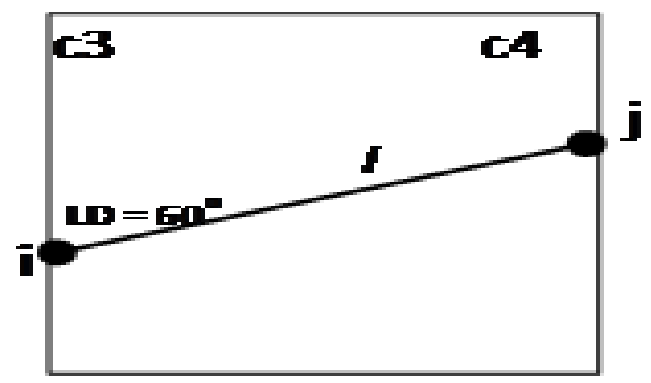

Fig. 16. Rectangular area

To find an optimal number, $T$ associated with allocating $L L$ (for $l=1$ to $L$ ). The $L L$ is line-length to be assigned into block $B$ relies on $i$ and $j$. Both $i$ and $j$ coordinates are acquired from the use of trigonometry function since the angle of line-direction $L D$ has been priory determined. The process of assigning $L L$ occurs with condition of $L L$ must be in range of the block coordinates. Furthermore, develop production $T$ with $L L$ is involved with every line $l$ in coordinate $i$ and $j$. However, the production $T$ drops due to existence of the unused area $a$ (for $a=1 \ldots n$ ) of the area..

According to the above matter, it can be written as follows:

1) To calculate tree number for a line-direction $f(T)$

$f(T)=\sum_{l=1}^{n} L D_{i j a} \quad l=1,2, \ldots, n$

Subject to: $l(\mathrm{i}, \mathrm{j})>=\mathrm{B}(\mathrm{c} 1, \mathrm{c} 2)$ and

$l(\mathrm{i}, \mathrm{j})<=\mathrm{B}(\mathrm{c} 3, \mathrm{c} 4)$

Refer to figure 14 , the $l$ coordinate increases for each assignment with formula $\mathrm{i}+$ row distance (r), j + row distance (r). Row distance is derived from the equation of $r$ $=\operatorname{sqrt}\left(d^{2}-(d / 2)^{2}\right)$ in which $d$ is the planting distance.

2) To calculate tree number of 90 line-directions for a block $f(B)$

$f(B)=\sum_{L D=1}^{n} f(T)_{L D} \quad L D=1,2, \ldots, n$

3) To calculate tree number of 90 line-directions for all blocks $f(T)$

Due to the area is divided to number of blocks, we extend the formula to total up $T$ from each block $f($ allB $)$

$f($ allB $)=\sum_{b=1}^{n} f(B)_{b} \quad b=1,2, \ldots, n$

\subsection{Ll-Cs Application}

The LP-CS application was inspired of the mentioned strategies. We employed Visual Basic version 6.0 to create the application interface and write programming code, and Microsoft Access version 2000 for our database. As shown in figure 17, the basic parameter of planting distance, coordinate area, scale according to user input.

The accurate result of tree number and unused space for each tree lining degree will be stored in a database for analyzing purpose whenever the analysis - Tree Number button is pressed.

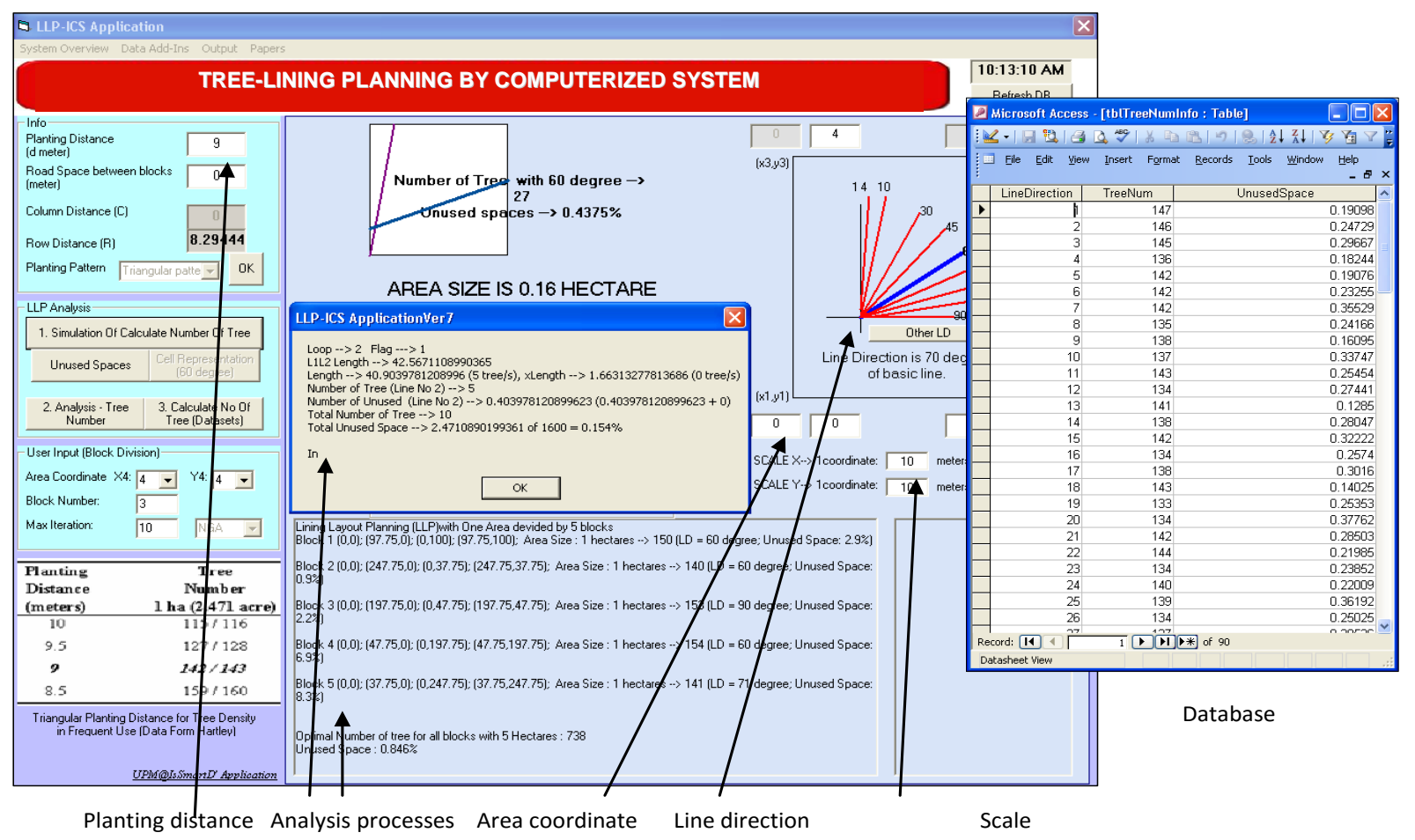

Fig.17. LP-CS Application 


\section{CASE STUDY}

The application chosen for the testing of the lining layout decision by algorithmic solution was Kampung Mang, Samarahan, Sarawak. This area organized by FELCRA for the project of oil palm plantations. The actual map and coordinate locations represented by digital, besides detail used and unused area as well as counting stands was provided for the purpose of analysis.

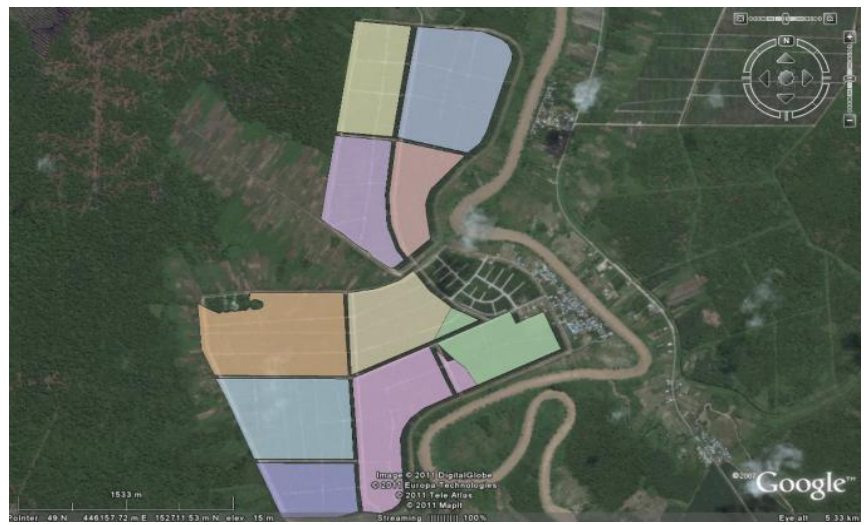

Fig.18. 10 block locations of the planting area

The planting is 400ha in area and it divided to 10 block locations, see figure 18. Each location divided by a main road and direction of tree lining based on the main road. The density of each area is varied because of the criteria of land area. The criteria were stated are road for main and field, drainage, building and areas are not be used.

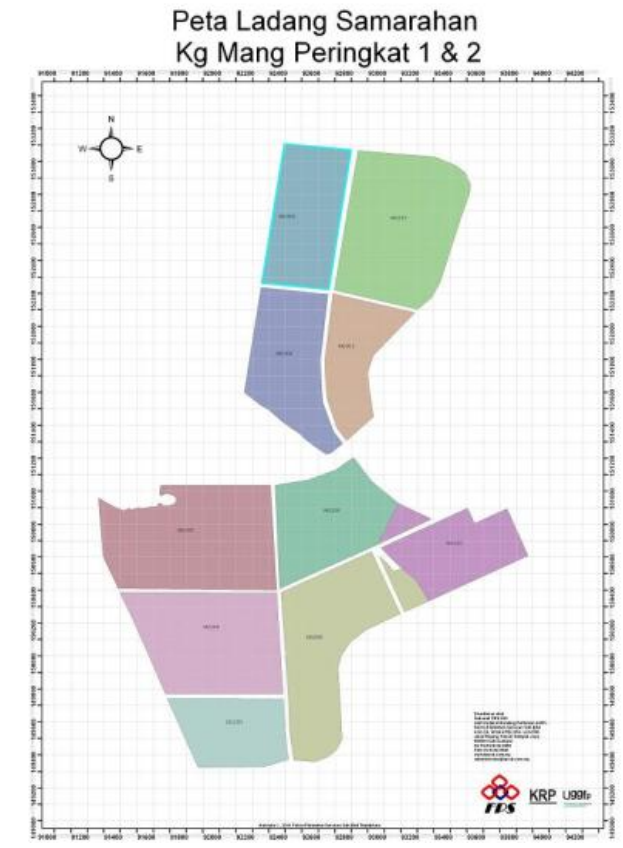

Fig.19. Map Location of Kampung Mang, Samarahan, Sarawak

Since the design on paper based on factors of full use of land, while the actual practice might produce inaccurate measurement, unexpected unused space and other factors, thus the comparison cannot be made directly.

\section{Standard Tree Density For Analysis Purposes}

To find the number of tree for common practice and LLP technique, a standard density was early determined which involved actual data and the published literatures. This density was used to determine number of tree for the selected areas.

From the 10 locations, we determine the actual number of tree of each and then find the average (data provided by felcra) as shown in table 1 .

Table 1. The actual number of tree from the 10 locations

\begin{tabular}{|l|l|l|l|}
\hline $\begin{array}{l}\text { Code } \\
\text { Location }\end{array}$ & Location & $\begin{array}{l}\text { Area } \\
\text { Size } \\
\text { (ha) }\end{array}$ & $\begin{array}{l}\text { Density } \\
\text { (stands per ha) }\end{array}$ \\
\hline A1 & MG1/01 & 29.35 & 145 \\
\hline A1 & MG2/01 & 42.74 & 135 \\
\hline A2 & MG2/02 & 45.97 & 141 \\
\hline A3 & MG2/03 & 31.05 & 129 \\
\hline A4 & MG2/04 & 36.52 & 144 \\
\hline A5 & MG2/05 & 32.54 & 143 \\
\hline A6 & MG2/06 & 45.78 & 133 \\
\hline A7 & MG2/07 & 56.37 & 141 \\
\hline A8 & MG2/08 & 50.86 & 124 \\
\hline A9 & MG2/09 & 30.13 & 135 \\
\hline & & 401.31 & 1370 \\
\hline
\end{tabular}

Our observation found that the ten locations with complete planted and unplanted areas by respectively promote 145 , $135 \ldots, 135$ trees.

Table 2. Tree number by considering the area is fully used

\begin{tabular}{|c|c|c|c|c||}
\hline \multirow{2}{*}{$\begin{array}{c}\text { Planting } \\
\text { Distance }\end{array}$} & \multicolumn{4}{|c|}{ Tree Density } \\
\cline { 2 - 5 } & Floor & \multicolumn{1}{|c|}{ Ceiling } & Nearest & Area is fully used \\
\hline & 163 & 164 & 164 & 163.6388795 \\
\hline & 139 & 140 & 140 & 139.55511 \\
\hline & 144 & 145 & 145 & 144.5431587 \\
\hline & 133 & 134 & 134 & 133.8466493 \\
\hline & 150 & 151 & 151 & 150.5319846 \\
\hline & 147 & 148 & 147 & 147.4710961 \\
\hline & 140 & 141 & 140 & 140.4753069 \\
\hline & 148 & 149 & 148 & 148.1025456 \\
\hline & 129 & 130 & 130 & 129.9505208 \\
\hline & 140 & 141 & 141 & 140.9596065 \\
\hline & 1433 & $\mathbf{1 4 4 3}$ & $\mathbf{1 4 4 0}$ & $\mathbf{1 4 3 9 . 0 7 4 8 5 8}$ \\
\hline $\mathbf{8 . 8}$ & $\mathbf{1 4 3 . 3}$ & $\mathbf{1 4 4 . 3}$ & $\mathbf{1 4 4}$ & $\mathbf{1 4 3 . 9 0 7 4 8 5 8}$ \\
\hline $\mathbf{9}$ & $\mathbf{1 4 0 . 1 1 5 5 6}$ & $\mathbf{1 4 1 . 0 9 3}$ & $\mathbf{1 4 0 . 8}$ & $\mathbf{1 4 0 . 7 0 9 5 4 1 7}$ \\
\hline
\end{tabular}

Based on the found data and then taking assumption of space is fully used as stated in table 2, the density (tree per hec) derived from fully used area divided by actual planted area and then the result is multiplied by actual number of tree. With panting distance of 8.8 and 9 the found tree density is 144 and 141 respectively.

The result shows, the found tree number by $9 \mathrm{~m}$ planting distance is 141 which is not much different that suggested by Harley (1967) and Turner (1974). For the purpose of analysis, standard density is 141 trees per ha $(25 * 4,25 * 4)$ with $9 \mathrm{~m}$ planting distance that generate by LLP application. 


\section{EXPERIMENTAL DESIGN}

Two types of dataset consist of artificial data and actual data were used for this experiment.

Artificial data represents coordinate area used for answering the tree density inconsistency and relation between number of tree and unused area. Besides that, the series of experiments by different coordinate of artificial data determined the best line direction for a land shape.

Actual data are based on the selected area of the case study. This experiment is to make comparison the number of tree produced by common practice and LP strategy. The results will answer the LP applicability for designing tree-lining in a planting area.

\subsection{Artificial Datasets}

The borders of the areas are varied; therefore, defining coordinates have to be completely collected to make sure the calculations for the number of trees, size of the area and unused space are accurate. For purpose of comparison, we create several artificial sets of data that represent area size as shown in tables 3 and table 4 . These tables show two different datasets with same area size; dataset1 uses coordinate of single-block and dataset 2 uses coordinates for five blocks that refers to the LP strategy. The blocks are represented by rectangular shapes with four coordinates each. The scale was used to represent the actual size of an area. The scale that represents $10 \mathrm{~m}$ means that $\mathrm{x} 4$ and $\mathrm{y} 4$ coordinates of each block were multiplied by 10 (e.g. in table 3 , it would be $223.61 * 223.61$ ) and it is equal to 5 hectares. With a $100 \mathrm{~m}$ scale, the area size is 500 hectares.

Table 3 Dataset1- One Area with Coordinates for a Single Block

\begin{tabular}{c|cccccccc}
\hline $\begin{array}{c}\text { Block } \\
\text { Type }\end{array}$ & $x 1$ & $y 1$ & $x 2$ & $y 2$ & $x 3$ & $y 3$ & $x 4$ & $y 4$ \\
\hline 81 & 0 & 0 & 22.361 & 0 & 0 & 22.361 & 22.361 & 22.361 \\
\hline
\end{tabular}

Table 4 Dataset2 - One Area with Coordinates for Five Blocks

\begin{tabular}{c|ccccccccc}
\hline $\begin{array}{c}\text { Bbck } \\
\text { Type }\end{array}$ & $\mathrm{xl}$ & $\mathrm{xl}$ & $\mathrm{yl}$ & $\mathrm{x} 2$ & $\mathrm{y}$ & $\mathrm{x} 3$ & $\mathrm{y} 3$ & $\mathrm{x} 4$ & $\mathrm{y} 4$ \\
\hline $\mathrm{B} 1$ & 0 & 0 & 0 & 10 & 0 & 0 & 10 & 10 & 10 \\
$\mathrm{~B} 2$ & 0 & 0 & 0 & 25 & 0 & 0 & 4 & 25 & 4 \\
B3 & 0 & 0 & 0 & 20 & 0 & 0 & 5 & 20 & 5 \\
B4 & 0 & 0 & 0 & 5 & 0 & 0 & 20 & 5 & 20 \\
B5 & 0 & 0 & 0 & 4 & 0 & 0 & 25 & 4 & 25 \\
\hline
\end{tabular}

\subsection{Real Dataset}

From the 10 locations, we have chosen A3 location for analysis purposes. The selection made based on the of land form since our focus area is rectangular.

The coordinate area for A3 as follow
Table 5. A3 Coordinate area of Kampung Mang, Samarahan, Sarawak

PROJECT: MG2/03
\begin{tabular}{|c|c|c|}
\hline & $X$ & $Y$ \\
\hline 1 & 92257.61617470000 & 152264.48668900000 \\
\hline 2 & 92661.77758220000 & 152226.25227200000 \\
\hline 3 & 92395.30729870000 & 153108.21522700000 \\
\hline 4 & 92797.14431570000 & 153070.85614600000 \\
\hline
\end{tabular}

From the above coordinate we manipulated to fulfill the system requirement in which the basic point of $x 1, y 1$ are 0 . Therefore, $\mathrm{x} 3$ and $\mathrm{y} 2$ were changed to 0 , while values of $\mathrm{x} 2$, $\mathrm{x} 4$ converted to 404.16140750000 and $\mathrm{y} 3, \mathrm{y} 4$ to 843.72853800000 as shown in figure $\mathrm{xx}$ in order to remain the size (product of $\mathrm{x} 4$ and $\mathrm{y} 4$ is 34.1 ha $(341002.51 \mathrm{~m})$ ) and form of shape (vertical rectangular) are same with actual coordinate.

Table 6 The coordinate of X, Y

\begin{tabular}{|l|l|l|}
\hline & $\mathrm{X}$ & $\mathrm{Y}$ \\
\hline 1 & 0.00000000000 & 0.00000000000 \\
\hline 2 & 404.16140750000 & 0.00000000000 \\
\hline 3 & 0.00000000000 & 843.72853800000 \\
\hline 4 & 404.16140750000 & 843.72853800000 \\
\hline
\end{tabular}

The coordinate of $\mathrm{x} 4, \mathrm{y} 4$ is used to find number of tree. We set the $\mathrm{x} 4$ is 4 and $\mathrm{y} 4$ is 8 coordinate and $\mathrm{x}$ and $\mathrm{y}$ represented by $101.04 \mathrm{~m}$ and is $105.47 \mathrm{~m}$ scale respectively. Some basic information also be initialized such as planting distance, space used between blocks, block number. Detail information as shown in table below:

Table 7 Basic Information of the selected area

\begin{tabular}{|l|l|}
\hline Variable & Value \\
\hline $\mathrm{x} 4$ shape & 4 \\
\hline y4 shape & 8 \\
\hline $\mathrm{x}$ scale & $101.04 \mathrm{~m}$ \\
\hline $\mathrm{y}$ scale & $105.47 \mathrm{~m}$ \\
\hline $\mathrm{x} 4$ size $(\mathrm{x} 4$ shape $*$ x4 scale) & $404.16140750000 \mathrm{~m}$ \\
\hline y4 size $(\mathrm{y} 4$ shape $*$ y4 scale) & $843.72853800000 \mathrm{~m}$ \\
\hline Area size & $34.1 \mathrm{ha}$ \\
\hline Planting distance & $9 \mathrm{~m}$ \\
\hline space used between blocks & $5 \mathrm{~m}$ \\
\hline Number of Block & 3 \\
\hline
\end{tabular}

\subsection{Procedures}

The planting distance is subject to user input, however in this experiment, we preferred to use the common distance in oil palm plantations which is $9 \mathrm{~m}$. Our assumption is that the areas were fully utilized, meaning that the trees could be assigned without considering the soil features and affected land factors. The areas that we focused on were flat. The 90 possibilities of line-direction $\left(1^{0}\right.$ to $\left.90^{\circ}\right)$ were assigned into areas. Thus, some information such as the area coordinate, blocks coordinate and baseline had been previously identified. The result generated by LP-CS for each line- 
direction was stated to be analyzed. The experiment was conducted several times using the provided datasets with the different scales as shown in table 8 .

Table 8 Four Types of the Experiment

\begin{tabular}{c|ccc}
\hline $\begin{array}{c}\text { Experiment } \\
\text { Number }\end{array}$ & Dataset & Scale & Area Size \\
\hline 1 & 1 & 10 & 5 hectares \\
2 & 2 & 10 & 5 hectares \\
3 & 1 & 100 & 500 hectar es \\
4 & 2 & 100 & 500 hectar es \\
\hline
\end{tabular}

\section{EMPIRICAL ANALYSIS, FINDING AND DISCUSSION}

\subsection{A Proof on Tree Density Inconsistency}

At the preliminary analysis, we conducted an experiment to demonstrate the tree number for same area size. First, we used the three coordinates of $(16,4),(8,8)$ and $(4,16)$ with the small size of all are $64 \mathrm{~m}^{2}$. Second, we increased the coordinates size to $(160,40),(80,80)$ and $(40,160)$ with all are 0.64 hectare. The results as shown in figure 18 and 19 .

In figure 20 , the optimal tree number of $(16,4),(8,8)$ and $(4,16)$ coordinates are 2,2 and 3 respectively, which is they reach the optimal at the different angle of line-directions. $60^{\circ}$ line-direction of $(8,8)$ and $(4,16)$ reach optimal number of tree and it shares with other line- directions. While for $(16,4)$ with optimal number of 3 is owned by line-direction of $77^{\circ}$ until $90^{\circ}$.

In figure 21, $(80,80)$ and $(40,160)$ coordinate produces 99 and 108 optimal tree number respectively at $60^{\circ}$ linedirection, while $(160,40)$ coordinates produces 107 trees at $30^{\circ}$ and $90^{\circ}$.

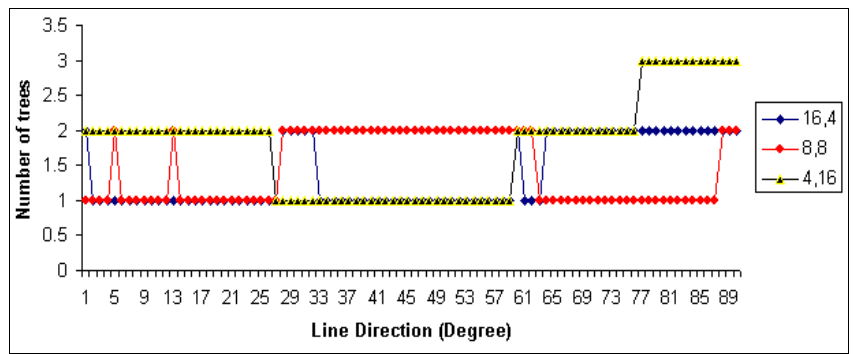

Fig.20. Comparison of Optimal Tree Number Produced By $(16,4),(8,8)$ and $(4,16)$ Coordinates

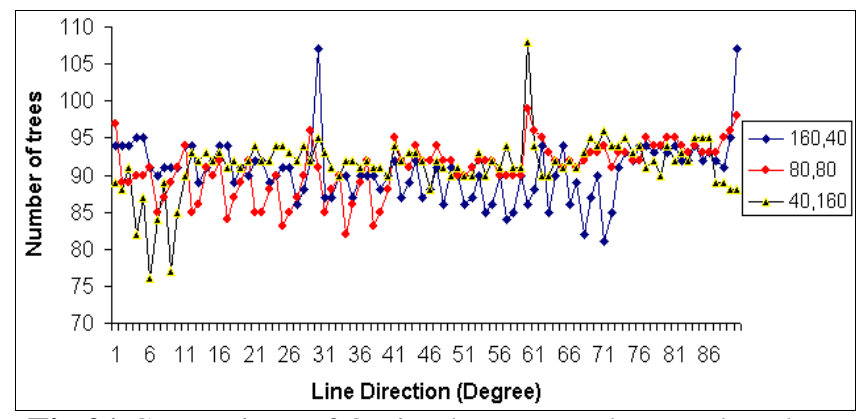

Fig.21.Comparison of Optimal Tree Number Produced By $(160,40),(80,80)$ and $(40,160)$ Coordinates
We initiate that even though the $60^{\circ}$ line-direction might reach optimal number of tree in many situations but it is not necessary for all other coordinates. Therefore, the common practice of using a $60^{\circ}$ line-direction in is not the best choice since it does not promise to achieve the highest number of trees.

Another analysis that involves a square area with coordinate of $x=100, y=100$, vertical rectangle with coordinate of $x=50$, $y=200$, horizontal rectangle with coordinate of $x=200, y=50$. All the rectangles by 1 hectare size at $60^{\circ}$ line-direction produce 150, 158 and 156 trees number respectively.

From the result, we found that even though area with same but different shapes does not necessarily obtain same number of tree. This is because of the calculated lines length are varied, thus promote to a difference of unused space.

\subsection{Relationship Of Unused Space And Number Of}

\section{Trees}

We believe that when the area is more utilized, it promotes better number of trees. For this, a comparison between tree number for each line-direction and its unused space by 1 hectare area size. As expected, the result showed a negative relation in which the lesser unused spaces basically promote more number of trees as shown in figure 22. Moreover, the optimal number of tree at $60^{\circ}$ has approximately $0.1 \%$ of unused space which is the smallest number.

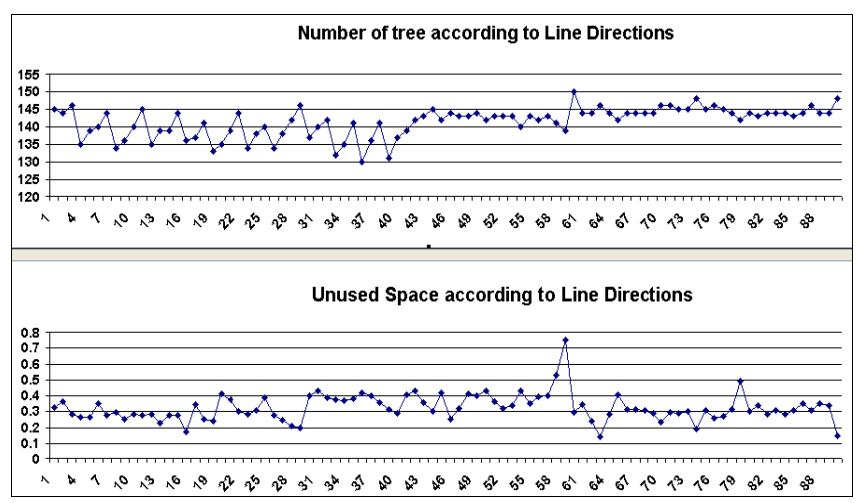

Fig. 22. Relationship between Number of tree and unused space

\subsection{Analysis Of LP Results}

Our hypothesis stated that the LP strategy provides the optimal lining layout by determining the best line-direction to promote better tree density in an area. We ran the LP-CS application using dataset 1 and dataset 2 to compare the results. The results were converted to graphs for analysis purposes.

In experiment 1 , the $60^{\circ}$ line-direction produced 725 trees which was the highest number compared to the other linedirections as shown in figure 23. In experiment 2, which consisted of blocks 1, 2, 3, 4 and 5, the best line-directions were $60^{\circ}$ with 150 trees, $60^{\circ}$ with 140 trees, $90^{\circ}$ with 153 trees, $60^{\circ}$ with 154 trees and $71^{\circ}$ with 141 trees respectively, 
as shown in figure 24 . The total number of trees in all blocks was 738 . The difference in the number of trees between experiment 1 and experiment 2 was 13

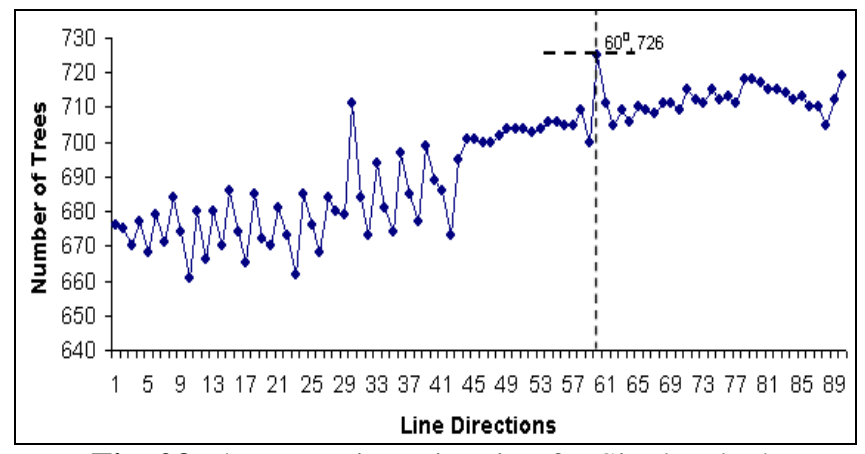

Fig. 23.The Best Line-Direction for Single Block

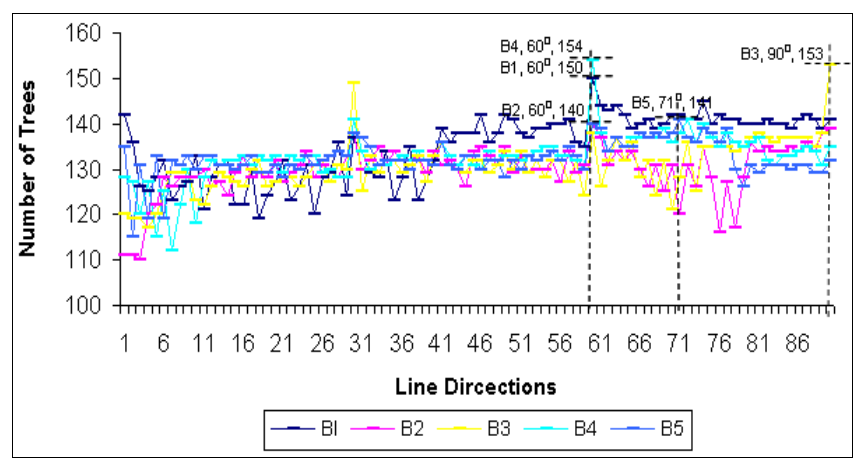

Fig. 24. The Best Line-Direction for Five Blocks

The difference in the number of trees between experiments 3 and 4 was more significant. Experiment 3 produced 72,088 trees at $80^{\circ}$, and experiment 4 produced 72,333 trees (B1 is 14416 trees at $82^{\circ}, \mathrm{B} 2$ is 14450 trees at $90^{\circ}, \mathrm{B} 3$ is 14230 trees at $77^{\circ}, \mathrm{B} 4$ is 14685 trees at $73^{\circ}$, B5 is 14552 trees at $68^{0}$ ) which resulted in a difference of 245 .

We conclude that the LP strategy promotes a better number of trees with 5 hectares and 500 hectares produced more than 18 and 245 respectively than common practice. Moreover, the difference of tree density in an area will be more significant when the area sizes are larger.

\subsection{Iteration Process}

In this section we attempt to make a comparison between cell representation and line-length representation in terms of effectiveness.

To represent a cell range for $60^{\circ}$ tree-lining angle with determined planting distance $(9 \mathrm{~m})$, the formula derives from planting distance divided by two $(9 / 2=4.5 \mathrm{~m})$ and multiplied by row distance $(7.8 \mathrm{~m})$. For instance the cells number within an area of 1 hectare that represented by 100 , 100 area coordinate and $9 \mathrm{~m}$ of planting distance requires 285 cells $(100 / 4.5) *(100 / 7.8)$. Whereas, the number of line representation derives from the iteration process generated by LP-CS when the lines are assigned. The comparison of both cell and line number is stated in table 6 .
Table 9. Number of analysis by Cell and Line Representation according to Area Coordinate

\begin{tabular}{|c|c|c|}
\hline $\begin{array}{c}\text { Area Coodinate } \\
(x 4, y 4)\end{array}$ & $\begin{array}{c}\text { Number } \\
\text { of Cell }\end{array}$ & $\begin{array}{l}\text { Number } \\
\text { of Line }\end{array}$ \\
\hline 40,40 & 46 & 9 \\
\hline 40,80 & 91 & 13 \\
\hline 80,40 & 91 & 12 \\
\hline 80,80 & 182 & 16 \\
\hline 100,100 & 285 & 20 \\
\hline 120,120 & 410 & 23 \\
\hline 160,160 & 729 & 30 \\
\hline 200,200 & 1140 & 37 \\
\hline 240,240 & 1641 & 44 \\
\hline 280,280 & 2234 & 51 \\
\hline
\end{tabular}

The graph of figure 25 that based on result in table 6 shows the same trend where both cell and line number increase when the area size increase. For all area coordinates, cell representation required more number of analyses than linelength representation. In addition, the number analysis by cell representation tremendously rose starting from area coordinate of $(100,100)$ onwards make the different analysis number of both are more significant.

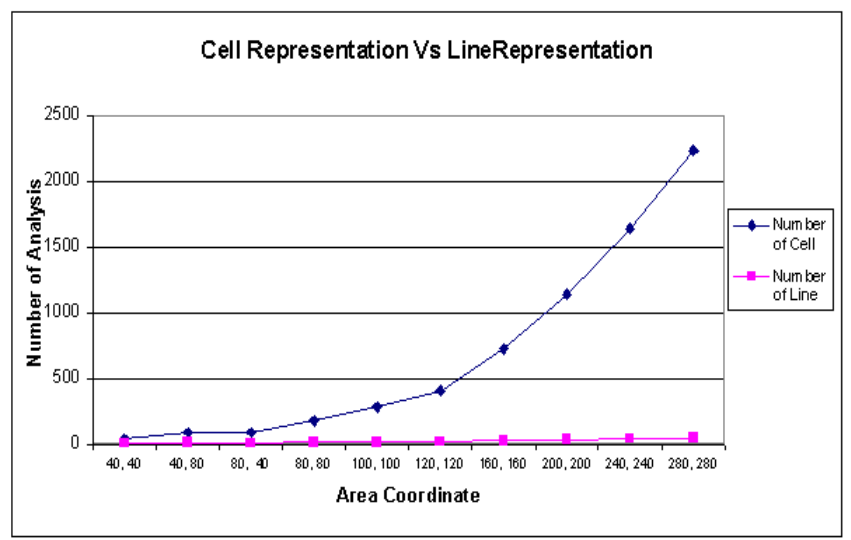

Fig.25. Number of Analysis Comparison between Cell and Line Representation

From the acquired results, we are optimistic that the linelength representation applied in LP-CS application has the capability to process the lining possibilities for tree number comparison in a large area by an acceptable amount of time. Using the line representation significantly reduces the iteration process and consequently the analysis can be implemented is more efficient. In addition, the use of line is more accurate to represent any tree-lining angles $\left(0^{0}\right.$ to $\left.90^{\circ}\right)$, whereas cell representation is applicable for $0^{\circ}, 45^{\circ}$ and $90^{\circ}$ as shown in figure 26. 


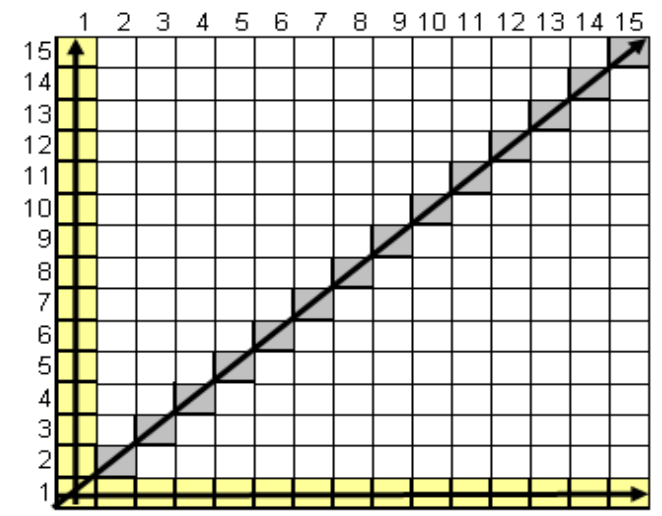

Fig. 26. Cell representation by $15 \times 15$ coordinate grid to produce lines according to tree-lining directions

\section{CONCLUSION}

The study on designing a tree-lining in planting areas is the first attempt to find an optimal solution. The LP strategy is practical for the practice of tree-lining planning. Although this paper focuses on the oil palm areas for as case study, the LP strategy is applicable for the other sectors that share similar goals. However, thorough studies are needed to determine the planting pattern, planting distance and constrain. Besides that, several issues such as tree quality and ease of management have to be deeply investigated. Thus, there are opportunities for researchers to conduct further research.

The inconsistency of tree density in a planting area caused by two factors which are the various areas coordinate and the existence of 90 possibility of line-direction. Thus, the unexpected tree density requires a computerized system for the purpose of optimizing land use. The LP-CS application does offer opportunities to determine tree density and subsequently find optimal solution for tree-lining planning. However, more than one line-direction that produces same optimal tree number leads to other considerations. Determining the best tree-lining with weighted consideration is a solution but large amount of computation time for analysis is a challenge.

In addition, the ability for LP-CS to analyze and propose the optimal combination of block makes this application intelligent. However, the strategy of assigning a pattern of shapes that represent blocks into an area could be considered as a matter of ambiguity. To solve this, a study is being conducted on an approximate technique strategy such as a genetic algorithm. The complexity in such problem was discussed by Ismadi et al. (2009) and it might require the efficient strategy for block division as to be applied in the LP-CS as suggested in the previous paper by Ismadi et al. (2012).

\section{ACKNOWLEDGEMENTS}

This research is registered under the Fundamental Research Grant Scheme (FRGS). The grant number is FRGS/03-04$10-873 F R / F 1$ and is fully funded by the Ministry of Higher Education (MOHE), Malaysia. The authors would like to express our highest appreciation and thanks to MOHE, Malaysia, and Universiti Teknologi MARA (UiTM), Malaysia, for sponsoring one of the authors to pursue a PhD. The authors also wish to thank the Universiti Putra Malaysia (UPM) for providing the facilities and conducive environments for conducting this research. Last but not least, the authors would like to express our gratitude to Federal Land Development Authority (FELDA), Malaysia and University Agriculture Park Department of UPM for giving us very good support and corporation in acquiring information.

\section{REFERENCES}

[1]. Appanah, S. and Weinland, G., 1993. Planting quality timber trees in Peninsular Malaysia. Malaysian Forest Record No. 38. FRIM, Kuala Lumpur. 221.

[2]. Blum, C. and Roli, A., 2003. Metaheuristic in Combinatorial Optimization: Overview and Conceptual Comparison, ACM Computing Survey Journal. $268-308$.

[3]. Chang, L.C., 2002. Expansion of oil palm planting in Malaysia. A paper submitted to MPOB management on a study on the potential area in the planting of oil palm in Malaysia especially Sabah and Sarawak.

[4]. Chemsain Consultant Sdn Bhd, 2000. Environmental Impact Assessment (EIA) Guidelines Oil Palm Plantation Development, Third Draft, November 2000. 10 .

[5]. Corley, R., H.V., Hew, C.K., Tam, T.K. and Lo, K.K., 1973. Optimal Spacing for Oil Palm. Paper presented in the International Oil Palm Conference. Incorporated Society of Planters, Kuala Lumpur. 1618 November 1972.52 - 71.

[6]. Harley, C.W.S., 1967. The Oil Palm. Book: Longman Publisher. 395.

[7]. Ian, E.H. And Mohd Tayeb, D, 2003. Physiological Analysis Of An Oil Palm Density Trial On A Peat Soil. Journal of Oil Palm Research Vol. 15 No. 2, December 2003, P. 1-27.

[8]. Ismadi, M.B, Abu Bakar M.S., Md Nasir, S., Ali, M., Mahmud, T.M.M., 2010. Shape Assignment by Genetic Algorithm towards Designing Optimal Areas, International Journal of Computer Sciences Issues (IJCSI) Volume 7, Issue 4, No5, Sept 2010, pp. 1-7.

[9]. Ismadi, M.B, Abu Bakar M.S., Md Nasir, S., Ali, M., Mahmud, T.M.M., 2009. Metaheuristic Approaches for Optimizing Agricultural Land Areas. Data Mining and Optimization Proceeding 2009, IEEE. 28 -31 .

[10]. Ismadi, M.B, Abu Bakar M.S., Md Nasir, S., Ali, M., Mahmud, T.M.M., 2012. An Efficient Strategy of Shape Assignment for Block Division. Data IJCSI International Journal of Computer Science Issues, Vol. 9, Issue 2, No 3, March 2012. 164 - 169.

[11]. Jusoh, L., Mohd Noor, Mohd Tayeb, D., and Ahmad Kushairi, D., 2003. Economic of Higher Planting Density in Oil Palm Plantations, Malaysia Palm Oil Board Journal. 32-39. 
[12]. Lamprecht, H., 1989. Culture in the Tropics. Tropical Forest Ecosystems and Their Tree Species Possibilities and Methods for their Long-term Utilization. GTZ, Eschborn, Germany. 296.

[13]. OP, 2010, Oil Palm. Available at <www.fertilizer.org> (accessed 20 January 2010).

[14]. Ramli, A., 2003. Short-Term and Long-Term, Projection of Malaysian, Palm Oil Production, Oil Palm Industry Economic Journal (Vol. 3(1)/2003), Malaysian Palm Oil Board. 32 - 36.

[15]. Safa, Mohammad Samaun, Ibrahim, Zahari and Abdul, Arifin, 2004. Potentialities of new line planting technique of Enrichment planting in Peninsular Malaysia: A review of resource sustainability and economic feasibility, KUSTEM 3rd Annual Seminar.

[16]. Theodor J., Steward, Tj., Rond Janssen, Marjan Van Herjinen, 2003. A Genetic Algorithm Approach to Multiobjective Land Use Planning, Computer and Operations Research. 2293 - 2313.

[17]. Turner, P.D. and. Gillbunks, R.A., 1974. Oil Palm Cultivation and Management, Book: The Incorporated Society of Planters. 1967-1977.

[18]. Wilson, A.B. and Piniau, J., 2004. Lining for Planting, New Britain Palm Oil Limited. P.O. Kimbe, West New Britain Province, Papua New Guinea. 114.

\section{BIOGRAPHIES}

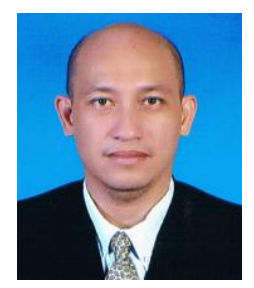

Ismadi is a doctoral lecturer in the faculty of Computer and Mathematical Sciences at Universiti Technolgy MARA (UiTM), Malaysia. He started as a lecturer in 2001, and was appointed as a senior lecturer in 2008. He obtained a Master's Degree with his research of timetabling system in 2002. In 2012, he was awarded the $\mathrm{PhD}$ in Intelligent Computing at University Putra Malaysia (UPM). His field of expertise are optimisation strategy and uncertainty problem solutions using evolutionary technquie.

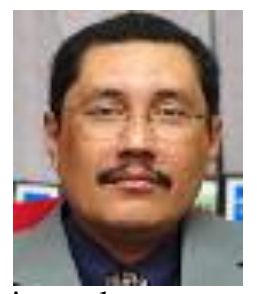

Abu Bakar is an Associate Professors and currently as dean faculty of the school of Computer Science and Information Technology, Universiti Putra Malaysia (UPM). His fields of expertise are Metaheuristic and Evolutionary Computing. He has published several journal papers regarding metaheuristic approaches and genetic algorithm in handling academic timetabling since 2004.

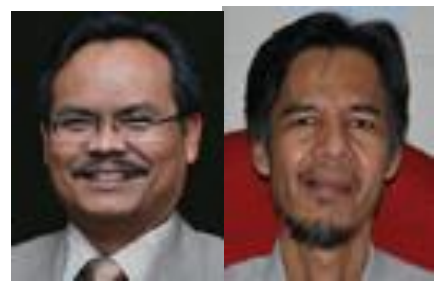

Nasir and Ali hold doctorates and are Associate Professors in the school of Computer Science and Information Technology, UPM. Nasir has expertise in Intelligent Computing, Intelligent Software Agent and Data Mining, whereas Ali's areas of expertise are Databases and XML.

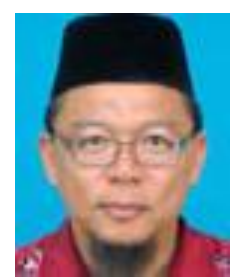

Mahmud is an Professor and $\mathrm{PhD}$ holder in Plant Physiology/ Post Harvest of Crop Sciences Department. His areas of expertise are Agricultural Sciences, Plant Physiology and Post-Harvest Physiology. $\mathrm{He}$ is currently the director of Agriculture Park, UPM. 